\title{
Determinação de Compostos Fenólicos em Vinho: Uma revisão
}

\section{Determination of Phenolic Compounds in Wine: A Review}

\author{
Edson Archela ${ }^{1}$; Luiz Henrique Dall’ Antonia ${ }^{2}$
}

\section{Resumo}

Um dos principais constituintes presentes nos vinhos é a classe de compostos fenólicos, que compreende os ácidos fenólicos, flavonóides, lignanas e estilbenos. Estes influenciam nas principais características dos vinhos como sabor, aparência, fragrância, adstringência e nas propriedades antimicrobianas. São os responsáveis pela diferença entre os vinhos branco e tinto. Além disso, esta classe de composto tem sido muito estudada por suas propriedades antioxidantes que, acredita-se, ajudar na prevenção de doenças, como certos tipos de câncer, doenças cardiovasculares, diabetes, acidentes vasculares cerebrais e outras doenças relacionadas ao envelhecimento. Por isso, é de grande interesse o desenvolvimento de métodos para a determinação de compostos fenólicos que sejam sensíveis, seletivos, rápidos e de fácil operação. O presente trabalho traz uma revisão dos métodos que vem sendo empregados para a determinação de fenólicos até o presente ano.

Palavras-chave: Compostos Fenólicos. Vinho.

\begin{abstract}
One of the main constituents in wines is the phenolic compounds that comprise the phenolic acids, flavonoids, lignans and stilbenes. Those have an important paper on the wines properties like flavor, appearance, astringent and antimicrobial properties. Moreover, phenolics have been extensively study in having antioxidant properties that may help in the prevention of disease like certain types of cancer, cardiovascular diseases, diabetes, strokes and other diseases related to aging. So is important the development of the phenolic compounds determination methods to be more selective, fast and easy operation. This paper brings a review of the methods employed on phenolics determination until this year.
\end{abstract}

Keywords: Phenolics Compouns. Wine.

\footnotetext{
Aluno de mestrado do Departamento de Química, Universidade Estadual de Londrina

2 Docente do Departamento de Química da Universidade Estadual de Londrina; luizh@uel.br
} 


\section{Introdução}

Os compostos fenólicos são aqueles que possuem uma, ou mais (polifenóis), hidroxilas ligadas a um anel benzênico e, embora contenha um grupo característico de álcoois, esta classe de compostos possui propriedades especiais, são compostos mais ácidos que os álcoois sendo oxidados com maior facilidade. Os fenóis incluem os compostos que possuam apenas um anel aromático ligado a um ou mais grupamentos hidroxílicos. Os polifenóis compreendem aqueles compostos fenólicos que possuam múltiplos anéis fenólicos em sua estrutura e podem ser divididos em classes de acordo com o número de anéis fenólicos e os elementos estruturais que ligam estes (Figura 1 e Figura 2) (WATERHOUSE, 2002). Eles podem, ainda, associar-se entre si, aumentando a complexidade e diversidade desta classe de compostos (Figura 3). A composição dos polifenóis nos alimentos pode variar com o tipo, época de colheita, fatores do meio ambiente, processamento e armazenamento (MANACH et al., 2004).

Figura 1 - Estruturas químicas de polifenóis.

\section{Ácido Hidroxidobenzóico}

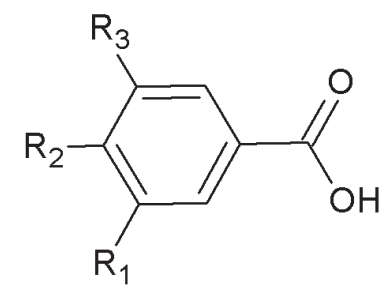

$\mathrm{R}_{1}=\mathrm{R}_{2}=\mathrm{OH}, \mathrm{R}_{3}=\mathrm{H}$ : Ácido Protocatecuico

$\mathrm{R}_{1}=\mathrm{R}_{2}=\mathrm{R}_{3}=\mathrm{OH}$ : Ácido Gálico

Flavonóides

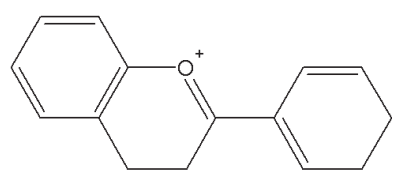

Ver Figura 2

\section{Estilbenos}

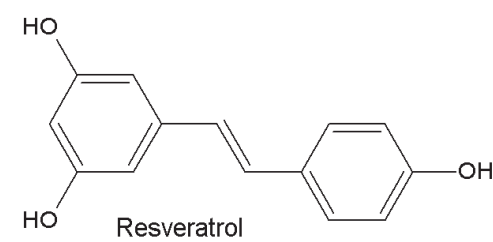

\section{Ácido Hidroxicinâmico}<smiles>[R]c1ccc(/C=C/C(=O)O)cc1[R]</smiles>

$$
\begin{aligned}
& \mathrm{R}_{1}=\mathrm{OH}, \mathrm{R}_{2}=\mathrm{H} \text { : Ácido Cumárico } \\
& \mathrm{R}_{1}=\mathrm{R}_{2}=\mathrm{OH} \text { : Ácido Caféico } \\
& \mathrm{R}_{1}=\mathrm{OCH}_{3}, \mathrm{R}_{2}=\mathrm{OH} \text { : Ácido Ferúlico }
\end{aligned}
$$

\section{Lignanas}<smiles>COc1cc([C@@H]2c3c(cc(OC)c(O)c3OC)C[C@H](CO)[C@@H]2CO)cc(OC)c1O</smiles>

Fonte: Dados dos autores. 
Figura 2 - Estruturas químicas dos flavonóides.

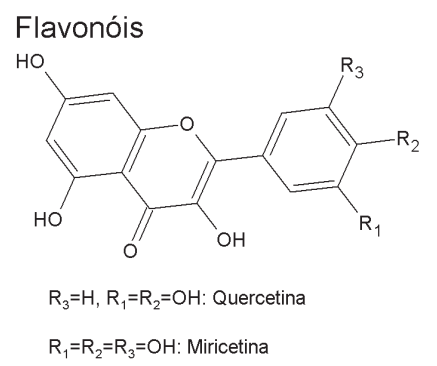

Flavonas

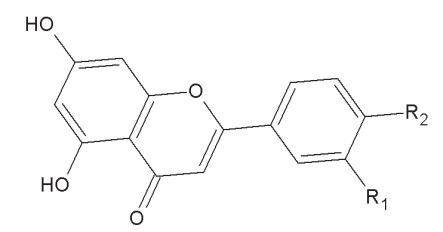

$\mathrm{R}_{2}=\mathrm{OH}, \mathrm{R}_{1}=\mathrm{H}$ : Apigenina

$\mathrm{R}_{1}=\mathrm{R}_{2}=\mathrm{OH}$ : Luteolina

Isoflavonas

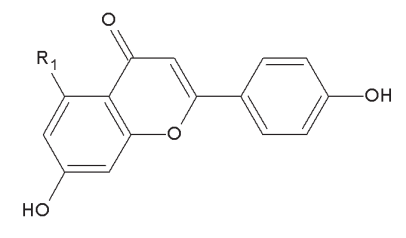

$\mathrm{R}_{1}=\mathrm{H}$ : Daidzeína

$\mathrm{R}_{1}=\mathrm{OH}:$ Genisteína
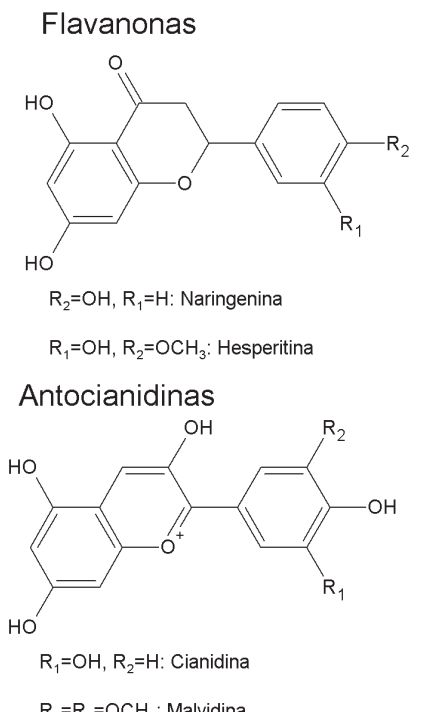

$\mathrm{R}_{1}=\mathrm{R}_{2}=\mathrm{OCH}_{3}$ : Malvidina

Flavanol

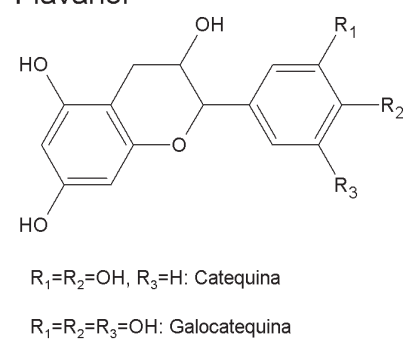

Fonte: Dados dos autores.

Figura 3 - Formação da procianidina pela polimerização de duas catequinas através da ligação dos carbonos 4 e 8.<smiles>Oc1cc(O)c2c(c1)O[C@H](c1ccc(O)c(O)c1)[C@H](O)C2c1c(O)cc(O)c2c1O[C@H](c1ccc(O)c(O)c1)[C@H](O)C2</smiles>

Fonte: Dados dos autores. 
Os dois grupos principais de polifenóis são os ácidos fenólicos e os flavonóides. Osácidos fenólicos podem ser classificados em ácidos benzóicos, e derivados, e ácidos cinâmicos, e derivados. Já os flavonóides possuem como subclasses principais os flavonóis, flavonas, flavanonas, isoflavonas e flavanóis (SATO et al., 1996).

Milhares de compostos fenólicos já foram identificados em plantas superiores, e centenas desses compostos são encontrados em plantas comestíveis. Estes compostos são metabólitos secundários das plantas, geralmente envolvidos na defesa contra organismos patogênicos ou raios ultravioletas. Assim, polifenóis estão disponíveis em uma ampla variedade de frutas, como limão, laranja, tangerina, uva, cereja, ameixa, pera e maçã (ANGELO; JORGE, 2007); legumes; verduras; e em alimentos e bebidas processados destes, como chá, vinho e outros.

Os principais fenólicos presentes na dieta humana são os flavonóides, os ácidos fenólicos e os taninos. Os flavonóides são compostos de baixo peso molecular que ocorrem, nas plantas, ligados a sacarídeos, na forma de glicosídeos, ou agliconas e sua estrutura pode ser apreciada na Figura 2 (KING; YOUNG, 1999). Os ácidos fenólicos podem ser divididos em derivados do ácidos hidroxibenzóico e hidroxicinâmico que conferem propriedades antioxidantes aos vegetais que os possuem (Figura 1). Já os taninos possuem alto peso molecular, consequência de várias polimerizações, e podem ser divididos em taninos condessáveis e hidrolisáveis (ANGELO; JORGE, 2007).

Dos compostos mais importantes presentes no vinho estão as antocianidinas e as procianidinas que são polimerizações dos monômeros citados na Figura 2, também chamados de taninos condensados (DELL'AGLI; BUSCIALÀ; BOSISIO, 2004).

Sabe-se que em comparação com os álcoois, os compostos fenólicos são muito mais ácidos devido à presença do anel benzênico que confere estabilidade aos produtos de oxidação dos fenóis.
Por serem mais ácidos, os polifenóis são oxidados antes que outras moléculas presentes nas plantas funcionando como antioxidantes para estas outras moléculas e protegendo a integridade de seu organismo formador (SOARES et al., 2008).

Em suma, os antioxidantes podem ser classificados em primários e secundários. Aqueles atuam interrompendo a cadeia de reação radicalar, reagindo com radicais para formarem produtos termodinamicamente estáveis ou complexos mais estáveis que o radical livre precursor; estes, os antioxidantes secundários, retardam a etapa que precede a formação dos radicais por diferentes mecanismos, como a complexação de metais, sequestro de oxigênio, decomposição de hidroperóxidos, absorção da radiação ultravioleta ou desativação de oxigênio singleto. Os fenólicos são classificados como antioxidantes primários (ANGELO; JORGE, 2007).

A atividade de um antioxidante é determinada pelo seu potencial de redução; a estabilidade do produto formado, que é regida pela capacidade de estabilizar e deslocalizar o elétron desemparelhado; a reatividade deste com outros antioxidantes; e a propensão de agirem como quelante de metais. Os polifenóis possuem a estrutura ideal para serem esses antioxidantes, pois possuem anéis benzênicos capazes de estabilizar os produtos oxidativo formados; além, de estes serem bons complexantes de metais, o que impede que eles hajam como catalizadores de reações radicalares (RICE-EVANS; MILLER; PAGANGA, 1997).

O oxigênio está presente na atmosfera na forma triplete $\left({ }^{3} \mathrm{O}_{2}\right)$, que é estável. Quando inalado ocorre um processo gradual de redução produzindo água, porém uma pequena quantidade de produtos intermediários instáveis, como o radical superóxido, radical hidroxil e peróxido de hidrogênio são formados. Estas espécies, chamadas de espécies reativas de oxigênio, podem iniciar a peroxidação dos lipídeos da membrana gerando acúmulo de peróxidos de lipídeo. Os produtos, primários e 
secundários, da peroxidação são altamente reativos, e reagem com substratos biológicos como proteínas, aminas e moléculas de DNA. Tal processo leva a doenças degenerativas. Embora os organismos vivos possuam mecanismos protetores contra as espécies reativas de oxigênio a eficiência destes processos decresce de acordo com o envelhecimento do organismo. Por tanto, sugere-se fornecer ao organismo moléculas que ajudem neste processo protetivo, como substâncias antioxidantes (SATO et al., 1996).

As propriedades antioxidantes dos compostos fenólicos instigaram muitos estudiosos a avaliar a influência desses compostos na prevenção de doenças, como certos tipos de câncer, doenças cardiovasculares, diabetes, acidentes vasculares cerebrais e outras doenças relacionadas ao envelhecimento (GAMELLA et al., 2006; FUSCO et al., 2010).

Parte importante destes estudos é avaliar a bioaviabilidade. Sabe-se que embora tais compostos estejam presentes em nossa dieta muitos destes possuem pouca atividade ou baixa absorção em nosso organismo. Por isso, o conhecimento sobre sua atividade in vivo é de grande importância para a compreensão dos efeitos dos polifenóis em nosso organismo.

A maioria dos polifenóis presentes em nossa dieta não são absorvidos diretamente pelo organismo, mas necessitam ser hidrolisados por enzimas intestinais ou pela microflora colônica. Além disso, são rapidamente eliminados do plasma sanguíneo, o que indica que o consumo de alimentos que os contêm deve ser diário para a manutenção da concentração dos mesmos no sangue. Dos compostos fenólicos disponíveis em nossa alimentação os flavanonas e isoflavanonas são os mais ativos em nosso organismo (MANACH et al., 2004).

Estudos têm inferido que os polifenóis, presentes nos vinhos tintos, protegem o sistema cardiovascular sendo oxidados antes que outras substâncias, como as lipoproteínas de baixa densidade, "colesterol mau" que quando oxidadas aderem às paredes de vasos sanguíneos e podem gerar aterosclerose (FRANKEL; KANNER, 1993). Este efeito antioxidante é característico da maioria dos compostos fenólicos, especialmente catequinas, ácidos fenólicos e antocianidinas monoméricas, que restringem a formação de nitrosaminas e outros compostos nitrosos em alimentos (KERRY; ABBEY, 1997). Correlações podem ser feitas entre o consumo de vinho e a redução de doenças do coração, câncer de mama, diminuição da taxa de mortalidade feminina, redução da diabetes tipo II (TOMERA, 1999).

O baixo risco de doenças cardiovasculares associado ao consumo de vinho tinto e altas quantidades de gordura saturada é conhecido popularmente como "Paradoxo Frances". Dentre os polifenóis que desempenham importantes funções na diminuição de doenças cardiovasculares existe o resveratrol, cujo vinho e uvas são sua principal fonte. O resveratrol tem chamado a atenção por possuir propriedades bioquímicas e fisiológicas como ações estrogênicas, antiplaquetária e anti-inflamatória. Em determinadas concentrações podem prover proteção contra doenças como aterosclerose, arritmias ventriculares e isquemia cerebral (LEKLI; RAY; DAS, 2009).

Sabe-se que a presença de espécies reativas de oxigênio e nitrogênio em um organismo vivo está associada ao aumento do risco de doenças crônicas, especialmente doenças cardiovasculares. Em contrapartida, o consumo de frutas, vegetais e vinhos, ricas fontes de substâncias antioxidantes provavelmente reduzem tal risco. Assim, conclui-se que a dieta de um indivíduo está relacionada com a probabilidade de este desenvolver doenças crônicas como doenças cardiovasculares, câncer, diabetes e outras (URQUIAGA et al., 2010).

No corpo, as maiores transformações dos polifenóis provenientes do vinho ocorrem no cólon, onde os metabólitos formados se tornam mais bioativos (SELMA; ESPÍN; TOMÁS-BARBERÁN, 
2009). Estes compostos ainda possuem a capacidade de inibir ou estimular o crescimento de diferentes bactérias no trato intestinal (REQUENA et al., 2010) e de diminuir a aderência das bactérias na cavidade oral, ajudando na prevenção de doenças bucais (HANNIG et al., 2009). Também, atuam como inibidores de cerca de $80 \%$ das atividades enzimáticas causadoras da cárie pelo estreptococo (THIMOTHE et al., 2007).

Urquiaga et al. (2010) estudou a influência do consumo diário de quantidades moderadas de vinho em duas dietas diferentes. Observou que o consumo moderado de vinho aumenta a concentração de polifenóis circulante no plasma e eleva a concentração de vitamina $\mathrm{C}$ presente no mesmo, o que aumenta a capacidade antioxidante deste, reduzindo danos ao DNA e às proteínas.

Sheu, Liu e Chen (2010) estudaram o efeito do resveratrol como agente protetivo contra os danos causados por estresse oxidativo ao epitélio pigmentar da retina e concluíram que o consumo de vinho pode amenizar a degradação deste. Outro estudo (SAKATA et al., 2010), revelou que o resveratrol induz a heme oxigênase 1 em culturas de células neurais de ratos fornecendo neuroproteção contra radicais livres ou danos excitotóxicos.

A saúde gastrointestinal e oral é outro ponto importante da saúde humana cuja dieta pode influir diretamente. Por possuir um alto conteúdo e diversidade de polifenóis, que são capazes de modificar seletivamente o crescimento de microorganismos susceptíveis, o vinho e derivados da uva tem chamado a atenção por possuírem potencial benéfico à saúde intestinal. Estudos tem mostrado que o consumo de bebidas com alto teor de compostos fenólicos tem efeitos contra a cárie dentária, em animais e humanos, pois inibe o crescimento e aderência dos micro-organismos causadores da carie à superfície do dente (HANNIG et al., 2009). Além disso, testes in vitro mostraram que alguns polifenóis e seus metabólitos podem inibir o crescimento de várias bactérias maléficas na microbiota humana sem produzir efeitos maléficos às bactérias probióticas (REQUENA et al., 2010).

Brouillard, George e Fougerousse (1997) também demonstrou que os polifenóis podem agir como protetores das moléculas do colesterol LDL contra a oxidação, o que ajuda na prevenção da aterogêneses que podem levar a ataques cardíacos.

Ortuño et al. (2010) demonstrou que o resveratrol é mais bem absorvido pelo corpo humano quando associado a matrizes biológicas, como o vinho e outros derivados da uva, que quando ingerido isoladamente.

Novos estudos a respeito da eficácia, segurança e dosagens de antioxidantes, para a prevenção de doenças, são necessários. Porém, a Food Standards Agency aconselha o consumo de vegetais, frutas e seus produtos uma vez que o consumo destes pode estar associado à redução do risco das doenças citadas (STANNER et al., 2003).

\section{Métodos para a Determinação de Fenólicos em Vinho}

O interesse pelos ácidos fenólicos e flavonoides tem aumentado devido a suas propriedades antioxidantes, cujos processos metabólicos e atividade em seres vivos ainda não foram completamente elucidados. Uma maneira de conhecer o potencial antioxidante desta classe de compostos em uma amostra alimentícia, como o vinho, é conhecer o índice de polifenóis totais desta amostra. Outras técnicas empregadas têm como objetivo a determinação de um composto específico ou grupo de compostos fenólicos.

A determinação dos fenólicos totais de matrizes alimentícias é difícil devido a uma série de fatores, como a ampla variedade de fenólicos, a complexidade química da matriz, a presença de interferentes e a dificuldade de extração destes da matriz. Como a determinação da concentração exata de fenólicos ainda não é possível utiliza-se uma estimativa da concentração total destes compostos, conhecida como índice de polifenóis totais. 
Tradicionalmente, o termo fenólicos totais se refere às medidas feitas por métodos espectrofotométricos, especialmente o método de Folin e Ciocalteu (1927). Porém mesmos estes apenas fornecem o índice de polifenóis totais (BLASCO et al., 2005).

Por se tratarem de uma classe muito ampla de compostos e estarem presentes nas mais diversas matrizes ainda não foi desenvolvido um método formal para a determinação.

Para o caso específico do vinho o método de Folin e Ciocalteu (1927) foi adotado como método oficial pela International Organization of Vine and Wine (2010). Porém, sabe-se que este método superestima o teor de fenólicos totais por estarem sujeitos a uma série de interferentes (EVERETTE et al., 2010).

\section{Métodos Espectrofotométricos}

O método de Folin e Ciocalteu (FOLIN; CIOCALTEU, 1927) foi desenvolvido originalmente para determinação de tirosinase. Porém, notaram em seu experimento que o triptofano, que não é um composto fenólico, também era sensível ao reagente desenvolvido produzindo espécies que, também, absorviam em $750 \mathrm{~nm}$, comprimento de onda utilizado no método. O reagente utilizado consiste na mistura de sais de molibidato de sódio, tungstato de sódio e outros reagentes. No teste, o grupo fenólico deve estar na forma de fenolato, afim de que os íons molibdato e tungsfosfato sejam reduzidos produzindo coloração azulada (as moléculas oxidadas são posteriormente decompostas em $\mathrm{pH}$ alcalino). Por isso, a cor formada também depende do número de hidroxilas ou de grupos potencialmente oxidáveis. Por reagir com moléculas facilmente oxidáveis este método encontra vários interferentes (ANGELO; JORGE, 2007).

Outros pesquisadores identificaram que o reagente de Folin e Ciocalteu também reagia com outras moléculas como proteínas, carboidratos, aminoácidos, nucleotídeos, tiol, ácidos graxos insaturados, vitaminas, aminas, aldeídos e cetonas (EVERETTE et al., 2010).

Atualmente, este método é adotado pela International Organization of Vine and Wine (2010) para a determinação do índice de polifenóis totais presentes em amostras de vinho.

Embora o método Folin-Ciocalteu seja o método de quantificação de compostos fenólicos mais extensivamente utilizado (SOUSA et al., 2007) outros métodos espectrofotométricos também são aplicados para medida de alguns fenóis específicos como o método de Maillard et al para a determinação de ácidos hidroxicinâmicos; o método de Mateos et al para a determinação de o-difenóis (BONOLI et al., 2004).

A espectroscopia de infravermelho com transformada de Fourier com módulo de refletância total atenuada (ATR-FTIR) pode ser utilizada sobre extratos de compostos fenólicos de amostras de vinhos para a diferenciação das qualidades de uvas utilizadas no processo de fabricação. Para isto utiliza-se a região do infravermelho médio que compreende os números de onda de 1800-900 cm-1 e representa a região de "fingerprint" dos vinhos (TARANTILIS et al., 2008).

Simonetti, Pietta e Testolin (1997) utilizaram o método desenvolvido por McMurrough e Baert (1994) para a determinação de flavanóis, utilizando $(+)$ catequina como padrão, e outros métodos para a quantificação do índice de fenólicos totais e flavonóis (livres e na forma glicosídica).

Mataix e Castro (2001) desenvolveram um método automatizado para a determinação do índice de polifenóis totais e densidade dos vinhos que se aproxima bem dos métodos oficiais de determinação. No artigo são otimizados dois métodos para a determinação do índice de polifenóis totais, o método Folin-Ciocalteu e um método direto, sem necessidade de preparação das amostras (exceto pela diluição destas), que utiliza o comprimento 
de onda de $280 \mathrm{~nm}$, porém este método é afetado pela presença de proteínas, ácidos nucléicos e aminoácidos que devem ser considerados na otimização do método (ANGELO; JORGE, 2007).

Outro método espectrofotométrico utilizando enzimas foi desenvolvido, também, para a determinação de fenólicos no vinho. O método consiste na oxidação dos fenólicos, catalisada pela peroxidase que, em seguida, reage com substratos aromáticos produzindo coloração intensa (STEVANATO; FABRIS; MOMO, 2004).

A espectroscopia no infravermelho próximo foi utilizada para a determinação simultânea de malvidina-3-glicosídeo, polímeros pigmentados e taninos durante a fermentação do vinho tinto. A malvidina-3-glicosídeo, uma antocianina, é responsável pela coloração avermelhada do vinho; já os polímeros pigmentados são polímeros derivados de antocianinas que representam moléculas de grande peso molecular e baixa polaridade e contribuem para a mudança de coloração e turbidez do vinho com o tempo. A radiação utilizada compreende dos comprimentos de onda de 750 a $2500 \mathrm{~nm}$ e provê informações acerca da proporção das ligações C-H, $\mathrm{N}-\mathrm{H}$ e O-H presentes nas estruturas analisadas. Porém estudos ainda são necessários para aumentar a exatidão do método (COZZOLINO et al., 2004).

\section{Métodos Cromatográficos}

Associados, ou não, aos métodos espectrofotométricos a cromatografia tem sido utilizada para análises mais detalhadas dos componentes fenólicos do vinho, tanto para identificação de compostos como para quantificação destes. Além de fornecer informações do teor total de compostos fenólicos presentes em uma amostra a cromatografia pode ser utilizada para determinação da concentração de grupos de compostos ou compostos específicos de fenóis presentes no vinho.

Brú et al. (1996) desenvolveram um método de extração líquido-líquido rotatório para a extração de compostos fenólicos de baixo peso molecular de amostras de vinho que possui vantagens sobre as extrações líquido-líquido convencionais como maior reprodutibilidade, rápida produção de extratos e a possibilidade de extrações simultâneas de 12 amostras diferentes. Este método não requer aquecimento em seu processo de extração, preservando melhor as amostras, além disso, o volume necessário de vinho para a extração rotatória é a metade do volume utilizado para a extração convencional. As amostras foram analisadas em um cromatógrafo líquido clássico.

Lamikanra et al. (1996) utilizaram a cromatografia gasosa para a determinação dos isômeros cis e trans da molécula resveratrol e outras moléculas da mesma classe de compostos. O método utilizou uma coluna capilar de $30 \mathrm{~m}$ de comprimento constituída de $95 \%$ de dimetil e $5 \%$ de difenil como fase estacionária e um detector de ionização em chama para a identificação dos compostos estilbeno hidroxilados.

No mesmo ano outro método foi proposto, agora utilizando cromatografia líquida de alta eficiência para a determinação de trans e cis resveratrol, glicosídeo trans-resveratrol, catequina, epicatequina, quercetina e rutina. O método constituí em utilizar a cromatografia líquida de alta eficiência com fase reversa, gradiente de eluente e um detector de diodos. O tempo de eluição desta técnica é de 40 mim (GOLDBERG et al., 1996).

Posteriormente foi proposto a utilização da cromatografia de alta eficiência com menor tempo de eluição (34 min). Neste método foi utilizada uma combinação de detectores de fluorescência e de absorbância (UV-VIS) para aumentar a seletividade e sensibilidade para a determinação de ácido siríngico, epicatequina e trans-resveratrol. Também foi utilizado um método de preparação da amostra utilizando extração líquido-líquido com dietil éter em pH 2,0 (RODRÍGUEZ-DELGADO et al., 2001).

Revilla et al. (2001) utilizaram um HPLC para separar antocianinas presentes no vinho tinto 
utilizando um gradiente linear de acetonitrila em água em $\mathrm{pH}$ 1,3, utilizando ácido perclórico como modificador de acidez (REVILLA et al., 2001).

Outro trabalho utilizando HPLC acoplado a detectores de UV e fluorescência permitiu a determinação de 15 compostos fenólicos: ácidos gálico, protocatecuico, vanílico, siríngico, cafeico, p-cumárico e ferúlico; catequina, epicatequina, quercetina, quercitrina, miricetina, kaempferol; e aldeídos siríngico protocatecuico (RODRÍGUEZDELGADO et al., 2002).

Em suma, o HPLC tem sido o método preferido devido sua versatilidade, precisão, relativo baixo custo e ausência de interferentes. Frequentemente, é utilizada fase reversa com colunas C18 ou C8 em conjunto com fase móvel aquosa e metanol ou acetonitrila como mistura (ESCARPA; GONZÁLEZ, 2001). Wang et al. (2002) fizeram um método para determinação de resveratrol utilizando um espectrômetro de massa acoplado ao HPLC. Castellari et al. (2002) otimizaram o método para injeção direta de amostras e determinação de 17 compostos fenólicos. Gambelli e Santaroni (2004) utilizaram a cromatografia líquida de alta eficiência para a análise do conteúdo fenólico de vinhos italianos com origem geográficos variados.

Recentemente, Nuengchamnong e Ingkaninan (2010) utilizaram o HPLC, acoplado a um espectrômetro de massa, trabalhando em sintonia com um espectrômetro UV-VIS para separação e identificação de alguns polifenóis. E, Dias et al (2010) utilizaram o HPLC, acoplado a um detector de fluorescência, para a determinação da catequina e epicatequina presente em vinhos tinto.

\section{Métodos Eletroquímicos}

Os métodos elétroquímicos tem sido muito empregados na determinação do potêncial redutor de compostos fenólicos, no estudo dos mecanismos de oxidação e para identificação de flavonóides (ANGELO; JORGE, 2007).
Garcia-Viguera e Bridle (1995) fizeram uma comparação entre a cromatografia líquida de alta eficiência e eletroforése capilar de zona concluindo que aquela é superior em termos de precisão, exatidão e sensibilidade, e esta possui vantagens econômicas e menor tempo de operação. O método eletroforético desenvolvido neste trabalho necessitou do dobro de concentração de amostra, quando comparado à sensibilidade do método cromatográfico. Assim, o autor indica um futuro desta técnica como método complementar ao cromatográfico.

Outro trabalho (CARTONI; COCCIOLI; JASIONOWSKA, 1995), otimizou as condições de separação dos compostos fenólicos, utilizando elétroforese capilar, para a análise destes compostos em vinho.

Arce et al. (1998) desenvolveram um método de eletroforése capilar com injeção de amostra contínua, preparada por uma coluna cromatográfica de C-18 utilizada para limpeza das amostras de vinho, para determinação de oito compostos fenólicos, dentre eles o trans-resveratrol.

$\mathrm{Gu}$ et al. (1999) alteraram as condições de trabalho de seu antigo método, para determinação de trans-resveratrol e cis-resveratrol em amostras de vinho, melhorando o limite de detecção, diminuindo o tempo de separação e a resolução dos picos do trans-resveratrol e cis-resveratrol (QINGYI; O'DWYER; ZEECE, 1998).

Cinco anos após a comparação feita por GarciaViguera e Bridle (1995), Gu et al. (2000) realizam outro teste comparativo entre a elétroforese capilar e a cromatografia líquida de alta performance e concluem que ambos possuem sensibilidade similar porém, a elétroforese capilar pode discriminar entre os isomeros cis e trans da molécula de resveratrosl além de ser método mais rápido.

A utilização da voltametria de pulso diferencial, com eletrodo de carbono vítreo, também pode ser utilizada na determinação de fenólicos totais, bem como na determinação seletiva de alguns flavonoides (BLASCO; GONZÁLEZ; ESCARPA, 2004). 
Blasto et al. (2005) desenvolveram um novo método para determinar os fenólicos totais em alimentos através da utilização de diferentes potenciais de forma a encontrar um índice para a capacidade antioxidante natural total, que foi chamada de índice eletroquímico. $\mathrm{O}$ método desenvolvido teve boa correlação $(r=0,95)$ com o método espectrofotométrico de Folin e Ciocalteu. Uma vez que, o método desenvolvido apresentou boa correlação, maior simplicidade e velocidade o autor sugere que este método seja usado como um novo protocolo para a obtenção do índice de polifenóis totais.

Volikakis e Efstathiou (2005) desenvolveram um método para determinação de flavonoides (quercetina, kaempferol, miricetina) utilizando voltametria adsortiva em um sistema de injeção em fluxo. Onde um eletrodo de pasta de carbono dopado com difenil éter foi utilizado para a preconcentração dos flavonoides, com o objetivo de eliminar outras espécies eletroativas.

\section{Biossensores}

Os métodos clássicos não podem ser aplicados com facilidade e são inviáveis para a indústria enológica, por necessitarem de mão de obra especializada e maquinário caro. Assim, surge a necessidade de métodos rápidos, baratos e de fácil operação. Abusca por métodos analíticos alternativos levou à junção entre a especificidade biológica e a sensibilidade eletroquímica. $\mathrm{O}$ biossensor eletroquímico mostrou-se uma boa alternativa para a detecção do conteúdo de compostos fenólicos uma vez que possui vantagens como fácil (ou nenhuma) preparação da amostra, seletividade, sensitividade, reprodutibilidade e baixo custo (FREIRE et al., 2003).
Segundo a IUPAC biossensores eletroquímicos são dispositivos capazes de fornecer informações quantitativas ou semiquantitativas de análises específicas por meio da utilização de um receptor biológico que é mantido em contato direto com um elemento de transdução eletroquímica (THÉVENOT et al., 2001). Dentre os receptores biológicos estão as enzimas, organelas, tecidos animal e vegetal, microrganismos, anticorpos, ácido nucléicos e outros. Ainda, os biossensores podem ser classificados, de acordo com o transdutor utilizado, como eletroquímico, entre estes potenciométrico, amperométrico e condutimétrico; óptico, entre estes com medidas de luminescência e fluorescências; e, detectores de massa (CORTES, 2008).

Um ponto crucial na construção de um biossensor é a imobilização da enzima sobre o eletrodo, pois com este processo a constante de ligação do substrato à enzima, a velocidade máxima desta reação, o pH ótimo para que a reação ocorra entre outros parâmetros podem variar. Para este processo costuma-se empregar procedimentos de ligação cruzada, ligação covalente, encapsulamento em géis ou membranas e, mais recentemente, impressão em eletrodos (FREIRE, 2002).

Os biossensores eletroquímicos, principalmente os potenciométricos e amperométricos, são os mais utilizados devido à facilidade operacional e alta sensibilidade inerentes ao método. Consistem na medida da variação de potencial e corrente, respectivamente, que acontecem quando o receptor biológico entra em contato com o analito.

Por trabalharem em baixo potencial os biossensores não possuem os mesmos problemas de interferências encontrados por outros eletrodos eletroquímicos convencionais (FREIRE, 2002). 
O primeiro biossensor foi proposto para oxidar a glicose em ácido glucônico usando um eletrodo para, amperometricamente, detectar o consumo de oxigênio, que é proporcional à concentração de glicose (STRADIOTTO; YAMANAKA; ZANONI, 2003). No caso de biossensores para determinação de fenóis o primeiro trabalho, que se tem notícia, foi feito por Hall, Best e Turner (1988), que utilizava um biossensor de tirosinase em meio orgânico para a determinação de p-cresol.

Biossensores para determinação de fenólicos tem utilizado enzimas como tirosinas, lacase e peroxidase, que são enzimas oxidases cujos compostos fenólicos são ótimos substratos. Desta forma os compostos fenólicos participam como doadores de elétrons para as enzimas. Na maioria dos casos é medido o conteúdo total de polifenóis. Estes biossensores são baseados em transdutores eletroquímicos que usam o ciclo redox das enzimas, diminuindo o número de interferentes, já que as enzimas são catalizadores muito específicos (MELLO; KUBOTA, 2007).

Para o caso da determinação de fenólicos em vinho, Rodríguez e Rivas (2002) desenvolveram um biossensor com eletrodo de pasta de carbono vítreo recoberto com a enzima polifenoloxidase de cogumelo purificada ou tecido de cogumelo fresco, usados como receptores biológicos.

Com o objetivo de aprimorar a utilização de biossensores para determinação de compostos fenólicos em vinhos, vários trabalhos foram publicados recentemente com diferentes receptores biológicos, como a lacase, tirosinase e peroxidase; transdutores; e formas de imobilização. A Tabela 1 (ver Apêndice) resume alguns dos resultados obtidos nestes trabalhos.

\section{Conclusões}

Grandes avanços têm sido contemplados para a análise de compostos fenólicos em alimentos, como o vinho, tanto na parte de aparelhagem como no desenvolvimento de melhores metodologias. Porém, em virtude da complexidade química das matrizes alimentícias avanços ainda são necessários para melhor controle dos fenólicos no pela indústria alimentícia, como maior seletividade, menor susceptibilidade à interferentes, menor custo operacional e rapidez.

\section{Agradecimentos}

Agradecimentos ao CNPq, CAPES e Fundação Araucária pelo auxílio financeiro.

\section{Referências}

ANGELO, P. M.; JORGE, N. Compostos fenólicos em alimentos - uma breve revisão. Revista Instituto Adolfo Lutz, São Paulo, v. 66, p. 232-240, 2007.

ARCE, L.; TERESA TENA, M.; RIOS, A.; VALCARCEL, M. Determination of trans-resveratrol and other polyphenols in wines by a continuous flow sample clean-up system followed by capillary electrophoresis separation. Analytica Chimica Acta, Amsterdam, v. 359, p. 27-38, 1998.

BLASCO, A. J.; ROGERIO, M. C.; GONZÁLEZ, M. C.; ESCARPA, A. "Electrochemical Index" as a screening method to determine "total polyphenolics" in food: A proposal. Analytica Chimica Acta, Amsterdam, v. 539, p. 237-244, 2005.

BLASCO, A. J.; GONZÁLEZ, M. C.; ESCARPA, A. Electrochemical approach for discriminating and measuring predominant flavonoids and phenolic acids using differential pulse voltammetry: towards an electrochemical index of natural antioxidants. Analytica Chimica Acta, Amsterdam, v. 511, p. 71-81, 2004.

BONOLI, M.; VERARDO, V.; MARCONI, E.; CABONI, M. F. et al. Antioxidant phenols in barley (Hordeum vulgare L.) flour: comparative spectrophotometric study among extraction methods of free and bound phenolic compounds. Journal of Agricultural and Food Chemistry, Washington, v. 52, n. 16, p. 5195-5200, 2004.

BÖYÜKBAYRAM, A. E.; KIRALP, S.; TOPPARE, L.; YAĞCI, Y. Preparation of biosensors by immobilization of polyphenol oxidase in conducting copolymers and their use in determination of phenolic compounds in red wine. Bioelectrochemistry, Amsterdam, v. 69, p. 164171, 2006. 
BROUILLARD, R.; GEORGE, F; FOUGEROUSSE, A. Polyphenols produced during red wine ageing. Biofactors, Oxford, v. 6, n. 4, p. 403-410, 1997.

BRÚ, E. R.; BARROSO, C. G.; CELA, R.; PEREZBUSTAMANTE, J. A. Development of a rotatory and continuous liquid-liquid extraction technique for phenolic compounds in wine. Analyst, London, v. 121, p. 297-302, 1996.

CAMPANELLA, L.; BONANNI, A.; FINOTTI, E.; TOMASSETTI, M. Biosensors for determination of total and natural antioxidant capacity of red and white wines: comparison with other spectrophotometric and fluorimetric methods. Biosensors and Bioelectronics, Essex, v. 19, p. 641-651, 2004.

CARTONI, G.; COCCIOLI, F.; JASIONOWSKA, R. Capillary electrophoretic separation of phenolic acids. Journal of Chromatography A, Amsterdam, v. 709, p. 209-214, 1995.

CASTELLARI, M.; SARTINI, E.; FABIANI, A.; ARFELLI, G.; AMATI, A. Analysis of wine phenolics by high-performance liquid chromatography using a monolithic type column. Journal of Chromatography $A$, Amsterdam, v. 973, p. 221-227, 2002.

CORTES, A. P. Biossensores para Dopamina: Lacase Imobilizada em Polissacarídeo. 2008. 88 p. Dissertação (Mestrado em Biotecnologia) - Universidade Estadual de Londrina, Londrina, 2008.

COZZOLINO, D.; KWIATKOWSKI, M. J.; PARKER, M.; CYNKAR, W. U.; DAMBERGS, R. G.; GISHEN, M.; HERDERICH, M. J. Prediction of phenolic compounds in red wine fermentation by visible and near infrared spectroscopy. Analytica Chimica Acta, Amsterdam, v. 513, p. 73-80, 2004.

DELL'AGLI, M.; BUSCIALÀ, A.; BOSISIO, E. Vascular effects of wine polyphenols. Cardiovascular Research, London, v. 63, p. 593-602, 2004.

DIAS, F. S.; LOVILlOC, M. P.; BARROSO, C. G.; DAVID, J. M. Optimization and validation of a method for the direct determination of catechin and epicatechin in red wines by HPLC/fluorescence. Microchemical Journal, New York, v. 96, p. 17-20, 2010.

ESCARPA, A.; GONZÁLEZ, M. C. Approach to the content of total extractable phenolic compounds from different food samples by comparison of chromatographic and spectrophotometric methods. Analytica Chimica Acta, Amsterdam, v. 427, p. 119-127, 2001.

EVERETTE, J. D. et al. Thorough study of reactivity of various compound classes toward the Folin-Ciocalteu reagent. Journal of Agricultural and Food Chemistry, Easton, v. 58, p. 8139-8144, 2010.
FERNANDES, C. I. S.; REBELO, M. J. F. Polyphenolic biosensors. Application in red wines. Portugaliae Electrochimica Acta, Aveiro, v. 27, p. 457-462, 2009.

FOLIN, O.; CIOCALTEU, V. On tyrosine and tryptophane determinations in proteins. The Journal of Biological Chemistry, Bethesda, v. 73, p. 627-650, 1927.

FRANKEL, E. N.; KANNER, J. Inhibition of oxidation of human low-density lipoprotein by phenolic substances in red wine. Lancet, London, v. 341, p. 454-457, 1993.

FREIRE, R. S. Efluente de indústria papeleira: processos alternativos para remediação e emprego de novas metodologias eletroanalíticas para determinação de compostos fenólicos. 2002. 194 p. Tese (Doutorado em Química) - Universidade Estadual de Campinas, Campinas, 2002.

FREIRE, R. S.; FERREIRA, M. M. C.; DURÁN, N.; KUBOTA, L. T. Dual amperometric biosensor device for analysis of binary mistures of phenols by multivariate calibration using partial least squares. Analytica Chimica Acta, Amsterdam, v. 485, p. 263-269, 2003.

FUSCO, M.; TORTOLINI, C.; DERIU, D.; MAZZEI, F. Laccase-based biosensor for the determination of polyphenol index in wine. Talanta, Oxford, v. 81, n. 1/2, p. 235-240, 2010.

GAMBELLI, L.; SANTARONI, G. P. Polyphenols content in some Italian red wines of different geographical origins. Journal of Food Composition and Analysis, San Diego, v. 17, p. 613-618, 2004.

GAMELLA, M. Electrochemical estimation of the polyphenol index in wines using a laccase biosensor. Journal of Agricultural and Food Chemistry, Easton, v. 54, p. 7960-7967, 2006.

GARCIA-VIGUERA, C.; BRIDLE, P. Analysis of noncolored phenolic compounds in red wines: a comparison of high-performance liquid chromatography and capillary zone electrophoresis. Food Chemistry, London, v. 54, p. 349-352, 1995.

GIL, D. M. A.; REBELO, M. J. F. Evaluating the antioxidant capacity of wines: a Laccase-based biosensor approach. European Food Research and Technology, Berlin, v. 231, p. 303-308, 2010.

GOLDBERG, D. M.; TSANG, E.; KARUMANCHIRI, A.; DIAMANDIS, E.; SOLEAS, G. Method to assay the concentrations of phenolic constituents of biological interest in wines. Analytical Chemistry, Washington, v. 68, p. 1688-1694, 1996.

GOMES, S. A. S. S.; REBELO, M. J. F. A new laccase biosensor for polyphenols determination. Sensors, Lausanne, v. 3, p. 166-175, 2003. 
GOMES, S. A. S. S.; REBELO, M. J. F.; NOGUEIRA, J. M. F. An amperometric biosensor for polyphenolic compounds in red wine. Biosensors and Bioeletronics, Essex, v. 20, p. 1211-1216, 2004.

GU, X.; CHU, Q.; O’DWYER, M.; ZEECE, M. Analysis of resveratrol in wine by capillary electrophoresis. Journal of Chromatography A, Amsterdam, v. 881, p. 471-481, 2000.

GU, X.; CREASY, L.; KESTER, A.; ZEECE, M. Capillary electrophoretic determination of resveratrol in wines. Journal of Agricultural Food Chemistry, Washington, v. 47, p. 3223-3227, 1999.

HALL, G. F.; BEST, D. J.; TURNER, A. P. F. The determination of $\mathrm{p}$-cresol in chloroform with an enzyme electrode used in the organic phase. Analytica Chimica Acta, Amsterdam, v. 213, p. 113-119, 1988.

HANNIG, C.; SORG, J.; SPITZMÜLLER, B.; HANNIG, M.; AL-AHMAD, A. Polyphenolic beverages reduce initial bacterial adherence to enamel in situ. Journal of Dentistry, Bristol, v. 37, n. 7, p. 560-566, 2009.

INTERNATIONAL ORGANIZATION OF VINE AND WINE. Update of the OIC compendium of methods of analysis of spirituous beverages of viticultural origin - overall determination of phenolic compounds in spirituous beverages of viticultural origin without added caramel. Disponível em: <http://news.reseau-concept. net/images/oiv_uk/client/OIV-OENO_382B-2010_ EN.pdf $>$. Acesso em: 25 jun. 2010

JÚNIOR, A. R. S.; REBELO, M. J. F. Biosensors for the polyphenolic content of wine determination. Portugaliae Electrochimica Acta, Aveiro, v. 26, p. 117-124, 2008.

KERRY, N. L.; ABBEY, M. Red wine and fractionated phenolic compounds prepared from red wine inhibit low density lipoprotein oxidation in vitro. Atherosclerosis, Limerick, v. 135, p. 93-102, 1997.

KING, A.; YOUNG, G. Characteristics and occurrence of phenolic phytochemicals. Journal of the American Dietetic Association, Chicago, v. 99, p. 213-218, 1999.

KIRALP, S.; TOPPARE, L. Polyphenol content in selected Turkish wines, an alternative method of detection of phenolics. Process Biochemistry, London, v. 41, p. 236-239, 2006.

LAMIKANRA, GRIMM, O. C. C.; RODIN, J. B.; INYANG, D. Hydroxilated stilbenes in selected American wines. Journal of Agricultural and Food Chemistry, Easton, v. 44, n. 4, p. 1111-1115, 1996.

LEKLI, I.; RAY, D.; DAS, D. K. Longevity nutrients resveratrol, wines and grapes. Genes and Nutrition, New Orleans, v. 5, n. 1, p. 55-60, 2009.
MANACH, C.; SCALBERT, A.; MORAND, C.; RÉMÉSY, C.; JIMÉNEZ, L. Polyphenols: food sources and bioavailability. The american Journal of Clinical Nutrition, Bethesda, v. 79, n. 5, p. 727-747, 2004.

MATAIX, E.; CASTRO, M. D. L. Simultaneous (or sequential) determination of the total polyphenol index (or I280) and density in wines by flow injection. Analyst, London, v. 126, p. 251-255, 2001.

MCMURROUGH, I.; VAERT, T. Identification of proanthocyanidins in beer and their direct measurement with a dual electrode electrochemical detector. Journal of the Institute of Brewing and Distilling, London, v. 100, p. 409-416, 1994.

MELLO, L. D.; KUBOTA, L. T. Biosensors as a toll for the antioxidant status evaluation. Talanta, Oxford, v. 72, p. 335-348, 2007.

MONTEREALI, M. R. L.; SETA, D.; VASTARELLA, W.; PILLOTON, R. A disposable Laccase-Tyrosinase based biosensor for amperometric detection of phenolic compounds in must and wine. Journal of Molecular Catalysis B: Enzymatic, Amsterdam, v. 64, p. 189-194, 2010.

. Tyrosinase biosensor based on modified screen printed electrodes: measurements of total phenol content. International Journal of Environmental Analytical Chemistry, New York, v. 85, p. 795-806, 2005.

NUENGCHAMMONG, N.; INGKANINAN, K. Online HPLC-MS-DPPH assay for the analysis of phenolic compounds in fruit wine: Antidesma thwaitesianum muell. Food Chemistry, London, v. 118, p. 147-152, 2010.

ORTUÑO, J.; COVAS, M. I.; FARRE, M.; PUJADAS, M.; FITO, M.; KHYMENETS, O.; ANDRESLACUEVA, C.; ROSET, P.; JOGLAR, J.; LAMUELARAVENTÓS, R. M.; TORRE, R. Matrix effects on the bioavailability of resveratrol in humans. Food Chemistry, London, v. 120, p. 1123-1130, 2010.

QINGYI, C.; O’DWYER, M.; ZEECE, M. G. Direct analysis of resveratrol in wine by micellar electro kinetic capillary electrophoresis. Journal of Agricultural and Food Chemistry, Easton, v. 46, p. 509-513, 1998.

REQUENA, T.; MONAGAS, M.; POZO-BAYÓN, M. A.; MARTÍN-ÁLVAREZ, P. J.; BARTOLOMÉ, B.; DEL CAMPO, R.; ÁVILA, M.; MARTÍNEZ-CUESTA, M. C.; PELÁEZ, C.; MORENO-ARRIBAS, M. V. Perspectives of the potential implications of wine polyphenols on human oral and gut microbiota. Trends in Food Science and Techenology, Cambridge, v. 21, p. 332-344, 2010. 
REVILLA, E.; GARCÍA-BENEYTEZ, E.; CABELLO, F.; MARTI-ORTEGA, G.; RYAN, J. M. Value of high-performance liquid chromatographic analysis of anthocyanins in the differentiation of red grape cultivars and red wines made from them. Journal of Chromatography A, Amsterdam, v. 915, p. 53-60, 2001.

RICE-EVANS, C. A.; MILLER, N. J.; PAGANGA, G. Antioxidant properties of phenolic compounds. Trends in plant science, Oxford, v. 2, p. 152-159, 1997.

RODRÍGUEZ, M. C.; RIVAS, G. A. Glassy carbon paste electrodes modified with polyphenol oxidase: analytical applications. Analytica Chimica Acta, Amsterdam, v. 459, p. 43-51, 2002.

RODRÍGUEZ-DELGADO, M. A.; MALOVANÁ, S.; PÉREZ, J. P.; BORGES, T.; GARCÍA MONTELONGO, F. J. Separation of phenolic compounds by highperformance liquid chromatography with absorbance and fluorimetric detection. Journal of chromatography A, Amsterdam, v. 912, p. 249-257, 2001.

RODRÍGUEZ-DELGADO, M.-Á.; GONZÁLEZHERNÁNDEZ， G.; CONDE-GONZÁLEZ， J.-E.; PÉREZ-TRUJILLO, J.-P. Principal component analysis of the polyphenol content in young red wines. Food Chemistry, London, v. 78, p. 523-532, 2002.

SAKATA, Y.; ZHUANG, H.; KWANSA, H.; KOEHLER, R. C.; DORÉ, S. Resveratrol protects against experimental stroke: Putative neuroprotective role of heme oxygenase 1. Experimental Neurology, San Diego, v. 224, p. 325$329,2010$.

SANZ, V. C.; MENA, M. L.; GONZÁLEZ-CORTÉS, A.; YÁÑEZ-SEDEÑO, P.; PINGARRÓN, J. M. Development of a tyrosinase biosensor based on gold nanoparticles-modified glassy carbon electrodes: Application to the measurement of a bioelectrochemical polyphenols index in wines. Analytica Chimica Acta, Amsterdam, v. 528, p. 1-8, 2005.

SATO, M.; RAMARATHNAM, N.; SUZUKI, Y.; OHKUBO, T.; TAKEUCHI, M.; OCHI, H. Varietal differences in the phenolic content and superoxide radical scavenging potential of wines from different sources. Journal of Agricultural and Food Chemistry, Easton, v. 44, p. 37-41, 1996.

SELMA, M. V.; ESPÍN, J. C.; TOMÁS-BARBERÁN, F. A. Interaction between phenolics and gut microbiota: Role in Human Health. Journal of Agricultural and Food Chemistry, Easton, v. 57, p. 6485-6501, 2009.

SHEU, S.; LIU, N.; CHEN, J. Resveratrol protects human retinal pigment epithelial cells from acroleininduced damage. Journal of Ocular Pharmacology and Therapeutics, New York, v. 26, n. 3, p. 231-236, 2010.
SIMONETTI, P.; PIETTA, P.; TESTOLIN, G. Polyphenol content and total anioxidant potentioal of selected Italian wines. Journal of Agricultural and Food Chemistry, Easton, v. 45, p. 1152-1155, 1997.

SOARES, M.; WELTER, L.; KUSKOSKI, E. M.; GONZAGA, L.; FETT, R. Compostos fenólicos e atividade antioxidante da casca de uva Niágara e Isabel. Revista Brasileira de Fruticultura, Jaboticabal, v. 30, p. 59-64, 2008.

SOUSA, C. M. D. M.; SOUSA, C. M. M.; SILVA, H. R. VIEIRA-JUNIOR, G. M.; AYRES, M. C. C.; COSTA, C. L. S.; ARAÚJO, D. S.; CAVALCANTE, L. C. D.; BARROS, E. D. S.; ARAÚJO, P. B. M.; BRANDÃO, M. S.; CHAVES, M. H. Fenóis totais e atividade antioxidante de cinco plantas medicinais. Química Nova, São Paulo, v. 30, p. 351-355, 2007.

STANNER, S. A.; HUGHES, J.; KELLY, C. N.; BUTTRISS, J. A review of the epidemiological evidence for the 'antioxidant hypothesis'. Public Health Nutrition, Wallingford, v. 7, n. 3, p. 407-422, 2003.

STEVANATO, R.; FABRIS, S.; MOMO, F. New enzymatic method for the determination of total phenolic content in tea and wine. Journal of Agriculturas and Food Chemistry, Washington, v. 52, n. 20, p. 6287-6293, 2004.

STRADIOTTO, N. R.; YAMANAKA, H.; ZANONI, M. V. B. Electrochemical sensors: a powerful tool in analytical chemistry. Journal of the Brazilian Chemical Society, São Paulao, v. 14, n. 2, p. 159-173, 2003.

TARANTILIS, P. A.; TROIANOU, V. E.; PAPPAS, C. S.; KOTSERIDIS, Y. S.; POLISSIOU, M. G. Differentiation of Greek red wines on the basis of grape variety using attenuated total reflectance Fourier transform infrared spectroscopy. Food Chemistry, London, v. 111, p. 192196, 2008.

THÉVENOT, D. R.; TOTH, K.; DURST, R. A.; WILSON, G. S. Electrochemical biosensors: recommended definitions and classification. Biosensors \& Bioelectronics, Barking, v. 16, n. 1/2, p. 121-131, 2001.

THIMOTHE, J.; BONSI, I. A.; PADILLA-ZAKOUR, O. I.; KOO, H. Chemical Characterization of Red Wine Grape (Vitis vinifera and Vitis Interspecific Hybrids) and pomace Phenolic Extracts and Their Biological Activity against Streptococcus mutans. Journal of Agricultural and Food Chemistry, Washington, v. 55, n. 25, p. 10200 10207, 2007.

TOMERA, J. F. Current knowledge of the health benefits and disadvantages of wine consumption. Trends in Food Science \& Technology, Cambridge, v. 10, p. 129-138, 
1999.

URQUIAGA, I.; STROBEL, P.; PEREZ, D.; MARTINEZ. C.; CUEVAS, A.; CASTILlO, O.; MARSHALL, G.; ROZOWSKI, J.; LEIGHTON, F. Mediterranean diet and red wine protect against oxidative damage in young volunteers. Atherosclerosis, Amsterdam, v. 211, n. 2, p. 694-699, 2010.

VOLIKAKIS, G. J.; EFSTATHIOU, C. E. Fast screening of total flavonols in wines, tea-infusions and tomato juice by flow injection/adsorptive stripping voltammetry. Analytica Chimica Acta, Amsterdam, v. 551, p. 124-131, 2005.

WANG, Y.; CATANA, F.; YANG, Y.; RODERICK, R.; VAN BREEMEN, R. B. An LC-MS method for analyzing total resveratrol in grape juice, cranberry juice, and in wine. Journal of Agricultural and Food Chemistry, Washington, v. 50, n. 2, p. 431-435, 2002.
WATERHOUSE, A. L. Wine phenolics. Annals New York Academy of Sciences, New York, v. 957, p. 21-36, 2002.

YANG, J.-H.; LEE, J.-C.; CHOI, S.-H. Tyrosinaseimmobilized biosensor based on the functionalized hydroxyl group-MWNT and detection of phenolic compounds in red wines. Journal of Sensors, New York, p. 1-9, 2009.

YILDIZ, H. B.; TOPPAREA, L.; GURSEL, Y. H.; YAGCI, Y. Immobilization of polyphenol oxidase in conducting graft copolymers and determination of phenolic amount in red wines with enzyme electrodes. Enzyme and Microbial Technology, New York, v. 39, p. 945-948, 2006.

YILDIZ, H. B.; KIRALP, S.; TOPPARE, L.; YAGCI, Y. Immobilization of tyrosinase in poly(ethyleoxide) electrodes and determination of phenolics in red wines. Reactive and Functional Polymers, Tokyo, v. 63, n. 2, p. 155-161, 2005. 


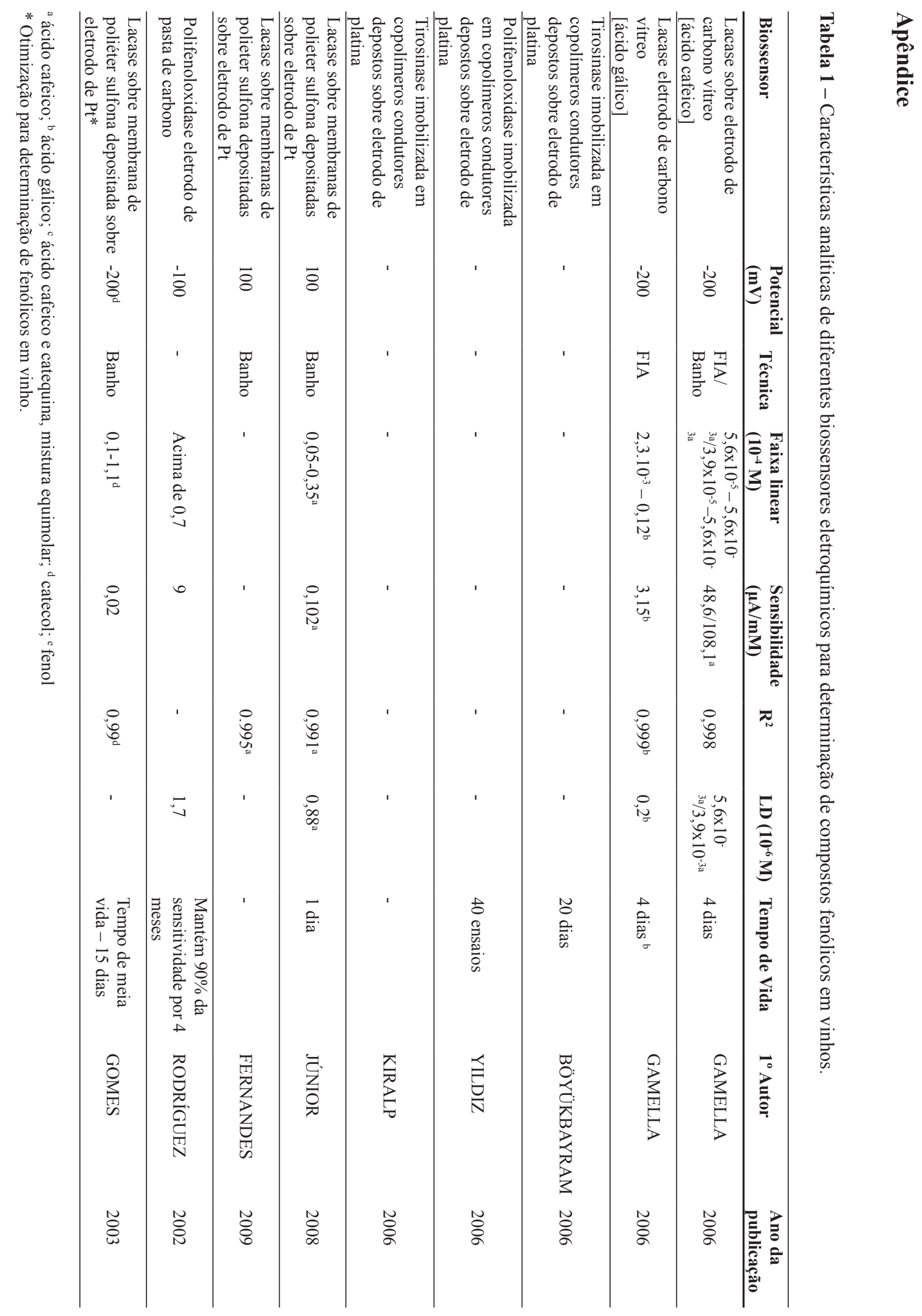




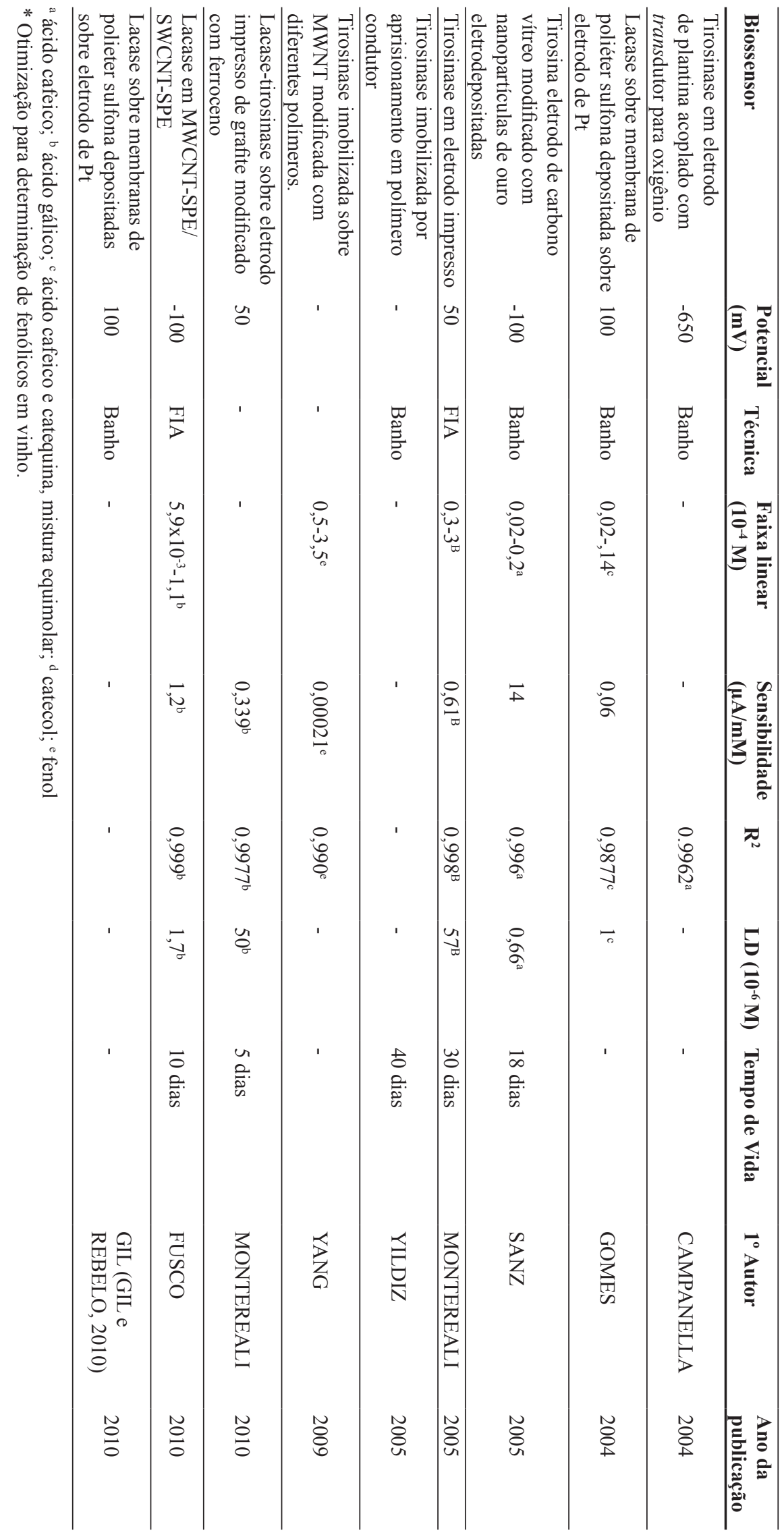


